\title{
An examination of the cumulative survival rate of narrow- diameter dental implants in the mandibular molar region: a retrospective cohort study
}

\author{
Keina Nagahisa, Korenori Arai* and Shunsuke Baba \\ Department of Oral Implantology, Osaka Dental University, Hirakata, Japan
}

\begin{abstract}
Introduction: Few reports have investigated narrow-diameter implant survival in the molar region.

Objective: The aim of this study was to compare the survival rates of narrow and regular-diameter implants in the mandibular molar region.

Material and methods: This retrospective cohort study included 638 patients who underwent implant treatment in the mandibular molar region at Osaka Dental University Oral Implantology Department and at six associated dental clinics from late December 2000 through to 2010. We investigated 1059 implants with attached superstructure, for which follow-up data were available in the medical records. Data on cumulative implant survival rates were analyzed in January 2016. In this study, we defined implants with a diameter of $3.5 \mathrm{~mm}$ as narrow-diameter implants (ND group) and those with a diameter of $3.75 \mathrm{~mm}$ or greater as regulardiameter implants (RD group). To calculate the implant survival rate, the Kaplan-Meier method was used.
\end{abstract}

Results: The cumulative implant survival rate after superstructure placement in the mandibular molar region was 97\% in both the RD group and the ND group at 183.0 months. According to the log-rank test, there were no significant differences between the ND and RD groups.

Conclusion: Narrow-diameter implants are equally successful in the mandibular molar region as regular-diameter implants.

\section{Introduction}

Several studies have reported implant survival rates after superstructure placement [1,2]. Other studies have reported on the utility of narrow-diameter implants in the anterior or premolar region $[3,4]$. However, there have been few reports investigating the survival of narrow-diameter implants in the molar region. In this report, the term "molar" refers only to the first and second molar region and excludes the premolars. A systematic review reported a comparison of implant survival rates according to implant diameter, site of implantation, location in the maxilla versus the mandible, and anterior versus molar region $[4,5]$. Implant survival rates with the combined use of guided bone regeneration (GBR) have also been reported [6,7], and no significant difference was found in the implant survival rate for implant therapy with versus without GBR $[8,9]$. Conventionally, regular-sized implants have been used with GBR in the narrow mandibular molar region instead of using narrow-sized implants, based on an assessment of mechanical intensity [10]. Sometimes GBR requires subsequent periodontal surgical treatment [11]. To provide minimally invasive implant therapy, the use of a narrow-diameter implant without GBR in the molar region would be preferable if there is no significant difference in implant survival rates between the methods. However, to date no studies have investigated the survival rate of narrow-diameter implants in the molar region [12]. Although some practitioners have placed narrow-diameter implants in the molars $[13,14]$, the practice has been applied predictively from personal perspectives and experiences, not based on the results of epidemiological studies. The aim of this study was to compare the cumulative survival rates of narrow-diameter versus regular-diameter implants in the mandibular molar region.

\section{Methods}

\section{Study design and setting}

This retrospective cohort study used existing data. The study group included patients who underwent implant therapy at six dental clinics associated with the Oral Implantology Department at Osaka Dental University from January 2000 through to December 2010. The study group was followed and cumulative implant survival rates were calculated at the time of data analysis in January 2016.

\section{Variables}

The data collected included patient background information (sex, age) and implant-related items. Variables were investigated at the last maintenance follow-up after placement of the implant superstructure. In addition, the variables involved the location of the implant site, the size (diameter, length) of the implant body, the manufacturer of the implant body, the operative method for implant placement, whether GBR was performed, the state of the opposing tooth, and the date of superstructure placement. Loss of the implant body after superstructure placement, and the presence or absence of peri-implantitis were also investigated.

Correspondence to: Korenori Arai, DDSc, Department of Oral Implantology, Osaka Dental University, 8-1, Kuzuha hanazono cho, Hirakata City, Osaka, Japan, Tel: +81-06-6910-1520; Fax: +81-06-6910-1048; E-mail: arai-k@cc.osaka-dent.ac.jp

Key words: narrow diameter, multivariate analysis, dental implant, failure

Received: July 02, 2017; Accepted: July 13, 2017; Published: July 18, 2017 


\section{Inclusion criteria}

Patients who had received implant therapy with attached superstructure in the mandibular molar region were included in this study.

\section{Exclusion criteria}

Patients who received implant therapy with anchor screws for orthodontic treatment, or patients who had not yet had the superstructure placed were excluded from this study.

\section{Statistical methods}

In this study, we stratified implant diameter into narrow size (ND group, $3.5 \mathrm{~mm}$ in diameter) versus regular size (RD group, $3.75 \mathrm{~mm}$ or more in diameter). The cumulative implant survival rates were calculated, after confirming cases in which the implant body was lost after superstructure placement. For ongoing evaluation of important markers of the patient's oral state, patients who had an interruption in maintenance follow-up visits of more than 6 months were excluded. When calculating cumulative implant survival rates, such patients were censored. Data were analyzed in January 2016.

Two factors were compared: 1 ) the cumulative rate of continuation of maintenance follow-up visits in the ND group versus the RD group; and 2) the cumulative implant survival rate in the ND group versus the $\mathrm{RD}$ group. To compare items related to treatment with patient characteristics and implant information, the chi square test was used for categorical data and the Mann-Whitney $U$ test was used for continuous numerical data. With both examination items, the two groups were compared with the log-rank test using the Kaplan-Meier method to describe the distribution. For statistical analysis, IBM SPSS Statistics Ver. 22 (IBM Corporation, New York, USA) was used.

This study protocol considered subjects' human rights and was approved by the ethical review board of Osaka Dental University (approval number: 110851).

\section{Results}

From 2000 through to 2010, 1655 patients underwent implant therapy in the Oral Implantology Department at Osaka Dental University. The total number of implants placed was 2469. In addition, 355 patients received a total of 1032 implants at associated dental clinics during the investigation period. A flow chart is shown in Figure 1. The number of implants with superstructure in the mandibular molar region was 1059; 563 of these were narrow diameter (ND group), and 496 were regular diameter (RD group). The ND group consisted only of implants with a diameter of $3.5 \mathrm{~mm}$, and the RD group had regular-sized implants, mostly $3.75-4.5 \mathrm{~mm}$, with some $5.0-5.5 \mathrm{~mm}$ in diameter. All implant bodies were made from titanium.

There were 328 patients in the ND group (114 males, 214 females; median age $54.8 \pm 9.6$ years) and 311 in the RD group (152 males, 159 females; median age $56.0 \pm 11.4$ years). There were significant differences between the groups in sex ratio, and in implant length between the groups when the sample was divided into implants $9.5 \mathrm{~mm}$ or less in length versus $10 \mathrm{~mm}$ or more before adjusting for each bias (Table 1).

Thirteen implants were lost in the RD group and 11 in the ND group. Peri-implantitis was the cause of nine lost implants in the RD group and 10 lost implants in the ND group. Other causes included breakage of the implant body and the abutment screw.
Table 1. Baseline characteristics of the study participants and implants.

\begin{tabular}{|c|c|c|c|c|}
\hline & & ND group & RD group & P value \\
\hline \multicolumn{2}{|c|}{ Patients Characteristics } & $(\mathrm{n}=328)$ & $(\mathrm{n}=311)$ & \\
\hline Sex -no. (\%) & Female & $214(65.2)$ & $159(51.1)$ & \\
\hline & Male & $114(34.8)$ & $152(48.9)$ & $<0.01^{\mathrm{a}}$ \\
\hline Age -yr & Overall & $54.8 \pm 9.6$ & $56.0 \pm 11.4$ & $<0.01^{\mathrm{b}}$ \\
\hline & $\begin{array}{c}\text { Among those } \geqq \\
65 \text { yr of age }\end{array}$ & $69.4 \pm 3.2$ & $70.5 \pm 3.4$ & $<0.01^{\mathrm{b}}$ \\
\hline \multicolumn{2}{|c|}{ Implants Characteristics } & $(\mathrm{n}=563)$ & $(\mathrm{n}=496)$ & \\
\hline Length -no. (\%) & $\leqq 9.5 \mathrm{~mm}$ & $225(40.0)$ & $167(33.7)$ & \\
\hline \multicolumn{2}{|c|}{$\geqq 10 \mathrm{~mm}$} & $338(60.0)$ & $329(66.3)$ & $<0.05^{\mathrm{c}}$ \\
\hline
\end{tabular}

ND group: implant diameter $(=3.5 \mathrm{~mm}$ in diameter $)$

RD group: implant diameter $(\geqq 3.75 \mathrm{~mm}$ in diameter $)$

a, c. Chi square test was used for categorical data.

b. Mann-Whitney U test was used for continuous numerical data.

In the ND group, $75 \%$ of patients were continuing maintenance follow-up visits at 93.5 months, compared with100.3 months in the RD group. This difference was not significant (Figure 2). Thus threequarters or more of total patients were included in the cohort and analyzed reliably. These results indicate that there was no bias when the cumulative implant survival rates were examined in both groups. The cumulative implant survival rate was $97 \%$ in each group at 183.0 months after superstructure placement in the mandibular molar region. The log-rank test showed no significant difference between the ND group and the $\mathrm{RD}$ group in cumulative implant persistence (Figure 3). For implant size, all items were analyzed with the Cox hazard model (Table 2).

\section{Discussion}

\section{Key result}

In areas with narrow bone, GBR has conventionally been used for implant treatment [10]. However, implant treatment with GBR imposes greater physical, mental, and financial burdens on patients because it is a surgically invasive procedure $[15,16]$. Therefore, in this study, we investigated the survival rate of narrow-diameter implants in the mandibular molar region. There were significant differences in the sex ratio and age ratio between the groups in this study. It has been reported that there is no sex-associated difference in cumulative implant survival rates; thus, sex was not considered to be a confounding factor $[17,18]$. No significant difference was observed in the cumulative implant survival rates in the mandibular molar region between the ND and $\mathrm{RD}$ groups. This finding suggests that narrow-diameter implants without GBR are equally suitable for use in the mandibular molar region as regular-diameter implants.

\section{Limitations}

The presence of confounders greatly influences the results of significant difference testing when evaluating cumulative implant survival rates. More events would need to be collected and analyzed in order to adjust for confounding factors. Specifically, to explore dropouts and implant body factors, approximately 10 or more events per factor would be required [19]. The number of events in both the ND and RD groups in this study was small. Therefore, it is difficult to infer conclusions about the causes of implant body dropout. This retrospective study did not evaluate narrow or regular diameter implants in terms of whether restoration was fixed, either singly or splinted to other implants or splinted to natural teeth. Additionally, the study did not take into consideration whether the opposing teeth were missing, whether they were natural teeth, or whether they were splinted to implants, crowns or removable partial dentures. In other cases, unknown events could have occurred in the patient population because 


\section{Flow chart}

Department of Oral Implantology, Osaka Dental University Hospital Dental clinic

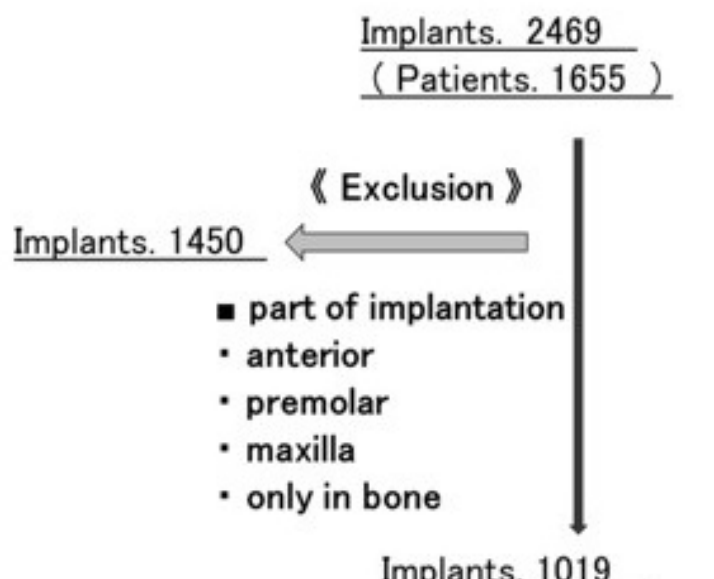

Implants. 1032 (Patients. 355 )

Implants. 1019

Implants. 363

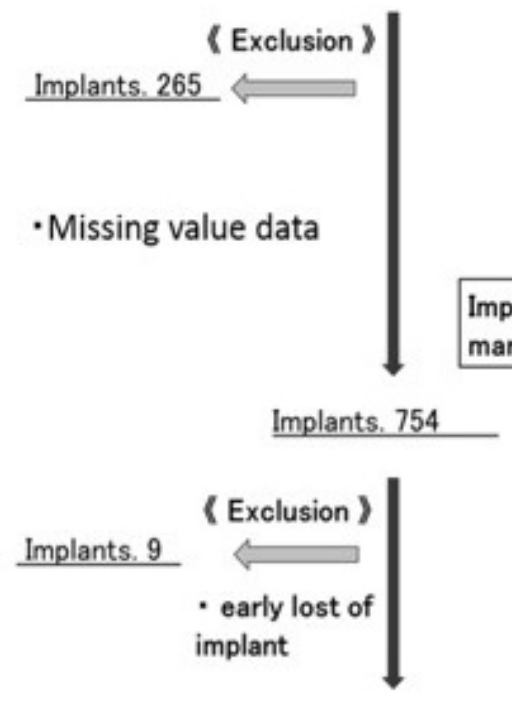

Implants. 762

\section{《Exclusion》}

Implants. 669

- part of implantation

- anterior

- premolar

- maxilla

- only in bone
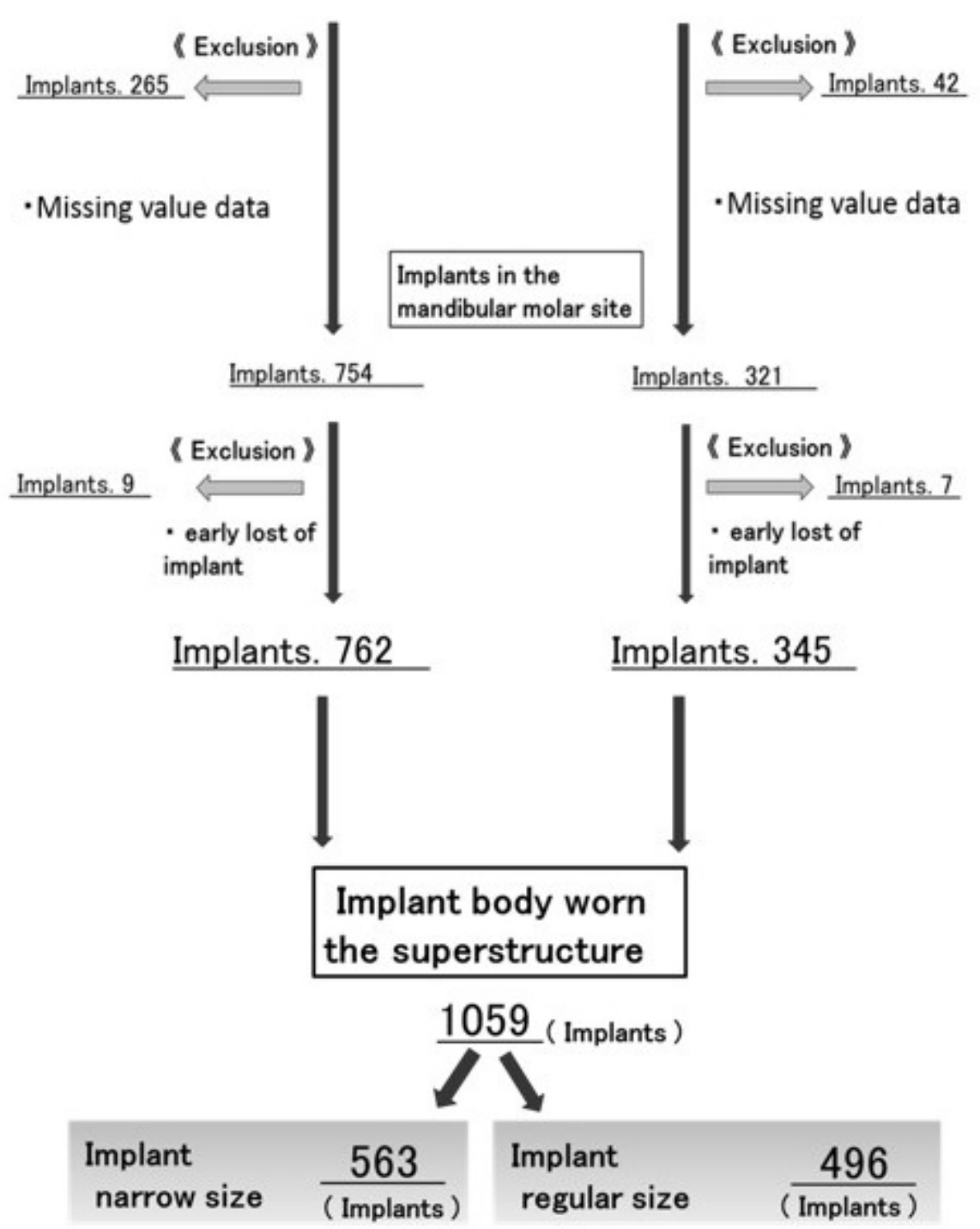

Figure 1. Flow chart: Background to the selection of targets. 
Table 2. Forest plot of primary outcome according to subgroups.

$\begin{array}{ccc}\text { ND group } & \text { RD group } & \text { Hazard Ratio }(95 \% \mathrm{CI})\end{array}$

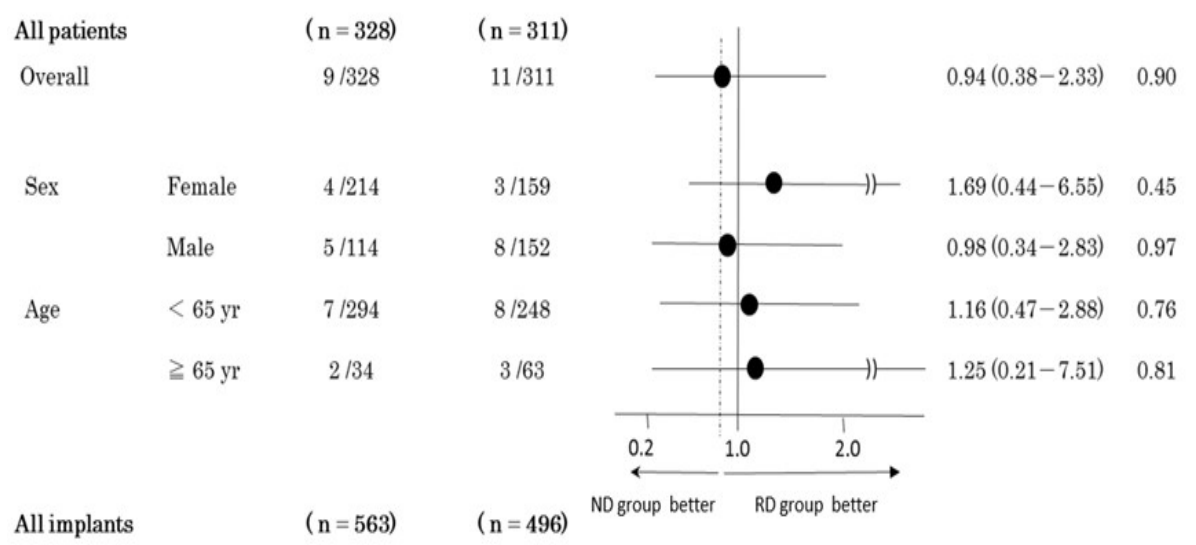

no. of implants no. of implants

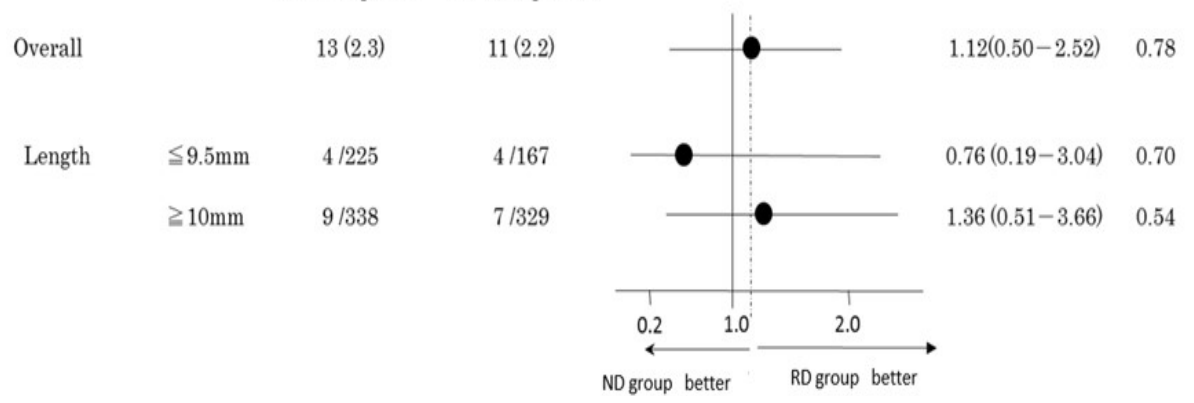

ND group: implant diameter $(3.5 \mathrm{~mm}$ in diameter)

RD group: implant diameter $(\geqq 3.75 \mathrm{~mm}$ in diameter $)$

The two groups were compared, with the log-rank test using the Kaplan-Meier method to describe the distribution, and for calculating the Hazard ratio, COX regression analysis was used.

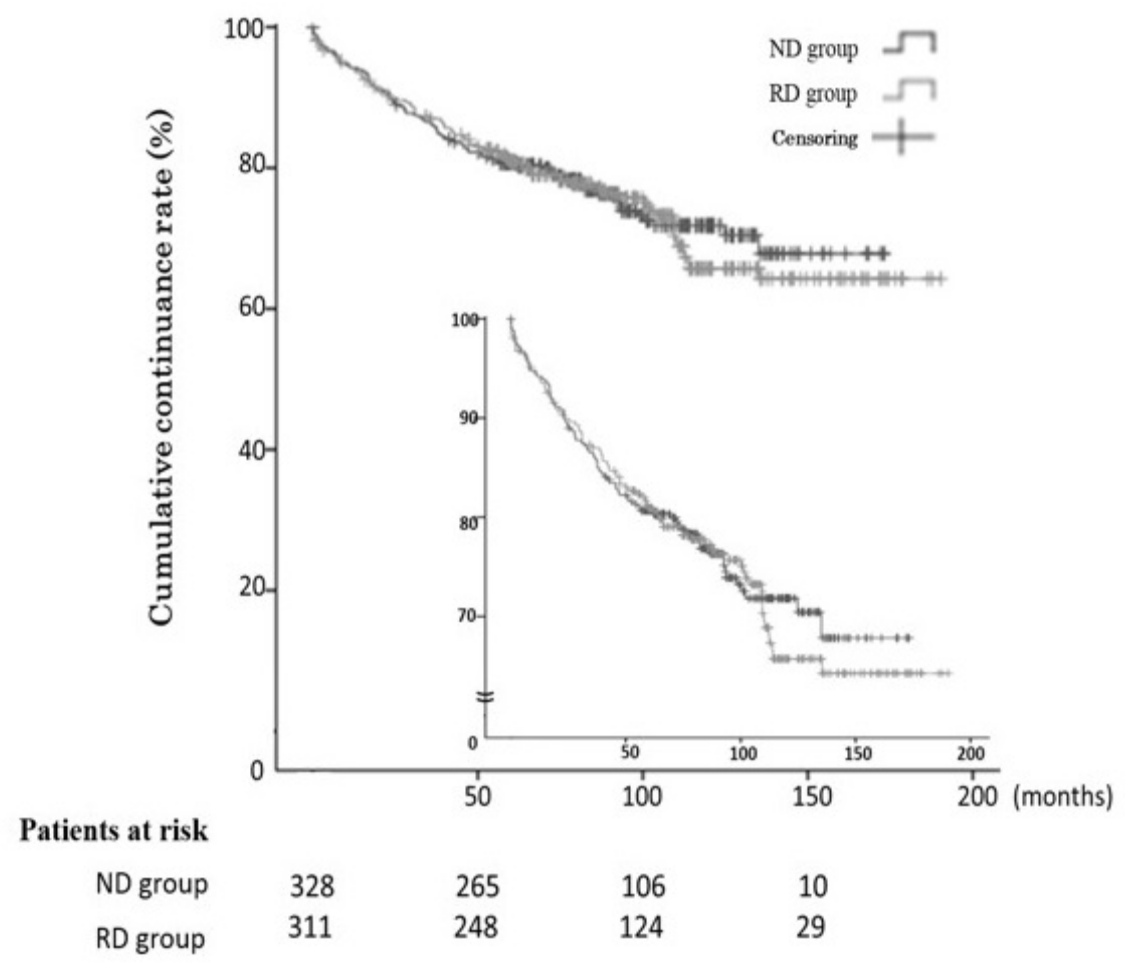

Figure 2. Maintenance accumulation continuance rate of the patients. 


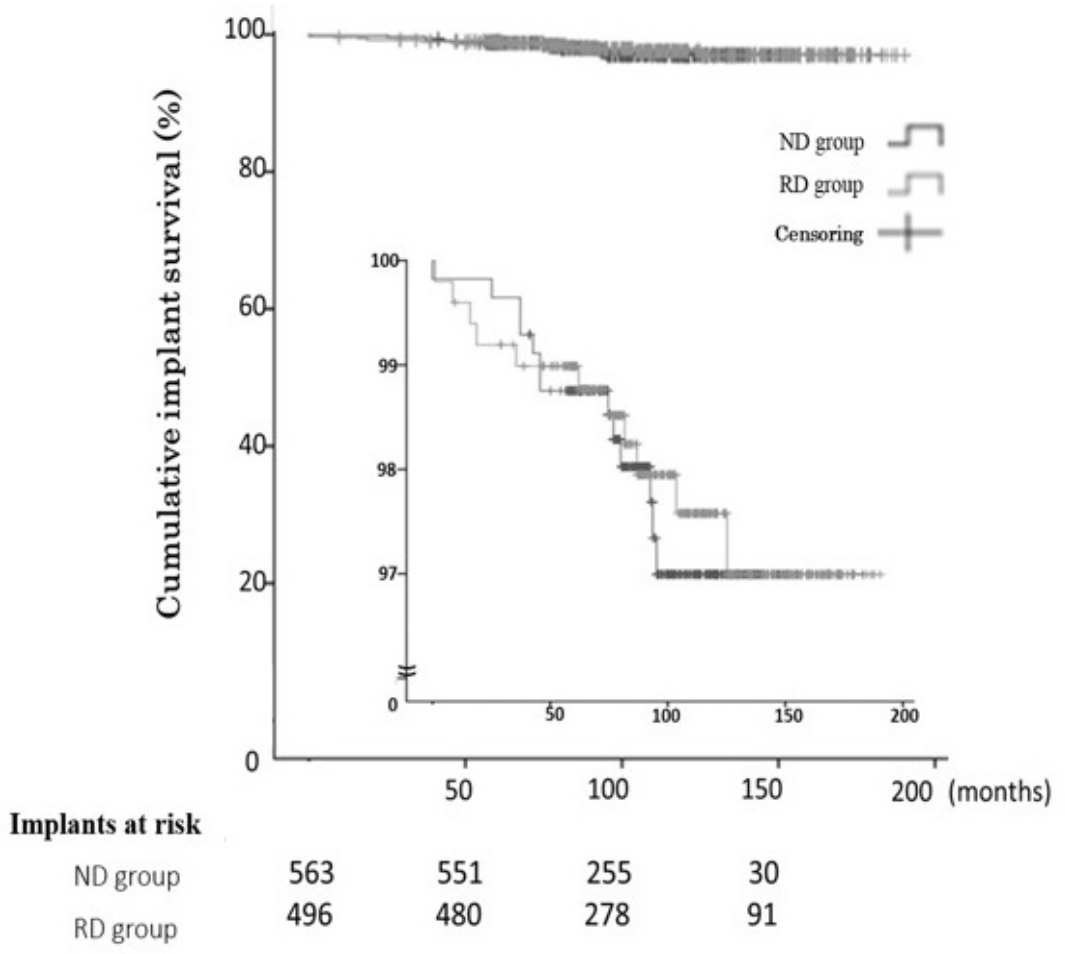

Figure 3. Implant survival rate in the mandibular molar region (ND group: implant diameter $=3.5 \mathrm{~mm}$; RD group: implant diameter $\geq 3.75 \mathrm{~mm}$ ).

patients discontinued maintenance follow-ups after placement of the superstructure. Therefore, the results of this study may overestimate the implant success rate. To improve the data, a reminder postcard could have been sent to all patients who stopped maintenance to encourage them to resume follow-up visits; this would assist in confirming implant survival after superstructure placement. The patients who interrupted maintenance included many elderly people, and patients who had reported the malfunction of the implants [20]. Because more dental visits are required as the Japanese population ages, cooperation will be necessary between patients treated with implants and local house-call dentists [21-23].

\section{Generalizability}

Data used in this study was collected from the Oral Implantology Department attached to Osaka Dental University and from six associated dental clinics; however, the generalizability of the results could be low. Future studies assessing longitudinal data from other organizations are required in the future. Japan currently has a medical database of medical institutions subject to the diagnosis procedure combination system, and the medical fee receipts for national health insurance and union insurance. By understanding the characteristics of these big datasets and mining them for information, observational studies have been conducted that are comparable to randomized controlled trials [24-27]. However, in the dental field, data concerning implants are not currently collected at many institutions [28]. To facilitate clinical studies for the development of implantology, it is necessary to build a database that will allow easy and rapid access to essential information.

\section{Conclusion}

This study found no difference in ongoing maintenance continuation between the ND and RD groups, and thus no related effect on cumulative implant survival rates. In implants placed in the mandibular molar region, there was no significant difference in cumulative implant survival rates between the ND group and the RD group. These results indicate that it is possible to increase the number of clinical cases that avoid treatment with guided bone creation, despite the decreased quantity of bone in the mandibular molar region. These findings suggest that minimally invasive implant treatment is acceptable.

\section{Acknowledgements}

We thank each of the associated dental clinics that cooperated in this study in various ways and the graduate students in the Department of Oral Implantology at Osaka Dental University, who assisted in preparing this article.

\section{Authors' contributions}

Study design: Korenori Arai; Analysis: Keina Nagahisa; Discussion: Korenori Arai and Shunsuke Baba.

\section{Conflicts of interest}

The authors have no conflicts of interest to report.

\section{References}

1. Moraschini V, Poubel LA, Ferreira VF, Barboza Edos S (2015) Evaluation of survival and success rates of dental implants reported in longitudinal studies with a follow-up period of at least 10 years: a systematic review. Int J Oral Maxillofac Surgery 44: 377 388. [Crossref]

2. Jung RE, Pjetursson BE, Glauser R, Zembic A, Zwahlen M, Lang NP (2008) A systematic review of the 5 -year survival and complication rates of implant-supported single crowns. Clin Oral Implants Res 19: 119-130. [Crossref]

3. Zinsli B, Sägesser T, Mericske E, Mericske-Stern R (2004) Clinical evaluation of small-diameter ITI implants: a prospective study. Int J Oral Maxillofac Implants 19: 92-99. [Crossref] 
4. Assaf A, Saad M, Daas M, Abdallah J, Abdallah R (2015) Use of narrow-diameter implants in the posterior jaw: a systematic review. Implant Dent 24: 294-306. [Crossref]

5. Renouard F, Nisand D (2006) Impact of implant length and diameter on survival rates. Clin Oral Implants Res 17: 35-51. [Crossref]

6. Pjetursson BE, Tan WC, Lang NP, Zwahlen M (2008) A systematic review of the success of sinus floor elevation and survival of implants inserted in combination with sinus floor elevation. Part I: Lateral approach. J Clin Periodontol 35: 216-240. [Crossref]

7. Tan WC, Lang NP, Zwahlen M, Pjetursson BE (2008) A systematic review of the success of sinus floor elevation and survival of implants inserted in combination with sinus floor elevation. Part II: Transalveolar technique. J Clin Periodontol 35: 241-254. [Crossref]

8. Jung RE, Fenner N, Hämmerle CHF, Zitzmann NU (2013) Long-term outcome of implants placed with guided bone regeneration (GBR) using resorbable and nonresorbable membranes after 12-14 years. Clin Oral Implants Res 24: 1065-1073. [Crossref]

9. Blanco J, Alonso A, Sanz M (2005) Long-term results and survival rate of implants treated with guided bone regeneration: a 5-year case series prospective study. Clin Oral Implants Res 16: 294-301. [Crossref]

10. Uoshima K, Fujii N, Yoshida K, Nagasawa M (2008) Dental Implant Clinics. Niigata Dent J 38: 1-14.

11. Tu YK, Needleman I, Chambrone L, Lu HK, Faggion Jr. CMf (2012) A Bayesian network meta-analysis on comparisons of enamel matrix derivative, guided tissue regeneration and their combination therapies. J Clin Periodontol 39: 303-314. [Crossref]

12. Klein MO, Schiegnitz E, Al-Nawas B (2014) Systematic review on success of narrowdiameter dental implants. Int J Oral Maxillofac Implants 29: 43-54. [Crossref]

13. Saad M, Assaf A, Gerges E (2016) The use of narrow diameter implants in the molar area. Int $J$ Dent 1-8.

14. Mazor Z, Lorean A, Mijiritsky E, Levin L (2012) Replacement of a molar with 2 narrow diameter dental implants. Implant Dent 21: 36-38. [Crossref]

15. Zancopé K (2015) Placement of a distal implant to convert a mandibular removable Kennedy class I to an implant-supported partial removable Class III dental prosthesis A systematic review. J Prosthet Dent 113: 528-533. [Crossref]
16. de Freitas RF, de Carvalho Dias K, de Fonte Porto Carreiro A, Barbosa GA, Ferreira MA (2012) Mandibular implant-supported removable partial denture with distal extension: a systematic review. J Oral Rehabil 39: 791-798. [Crossref]

17. Jang HW, Kang JK, Lee K, Lee YS, Park PK (2011) A retrospective study on related factors affecting the survival rate of dental implants. J Adv Prosthodont 3: 204-215. [Crossref]

18. Zupnik J, Kim SW, Ravens D, Karimbux N, Guze K (2011) Factors associated with dental implant survival: a 4-year retrospective analysis. J Periodontol 82: 1390-1395. [Crossref]

19. Austin, Peter CPC (2013) The performance of different propensity score methods for estimating marginal hazard ratios. Stat Med 32: 2837-2849. [Crossref]

20. de Araujo Nobre, Miguel A, Oliveira SH (2014) Associations of clinical characteristics and interval between maintenance visits with peri-implant pathology. J Oral Sci 56 : 143-150. [Crossref]

21. Arai K, Takeda Y, Mori Y, Terauchi R, Furumori T, et al. (2015) Analysis of factors associated with maintenance discontinuation in implant patients. Springerplus 4: 767 [Crossref]

22. Ikebe K (2010) Subjective values of different treatments for missing molars in older Japanese. J Oral Rehabil 37: 892-899. [Crossref]

23. Matsuda K, Kurushima Y, Enoki K, Ikebe K, Maeda Y (2014) Replacement of a mandibular implant-fixed prosthesis with an implant-supported overdenture to improve maintenance and care. J Prosthodont Res 58: 132-136. [Crossref]

24. Dahabreh IJ, Kent DM (2014) Can the learning health care system be educated with observational data? JAMA 312: 129-130. [Crossref]

25. Tanaka S, Tanaka S, Kawakami K (2015) Methodological issues in observationa studies and non-randomized controlled trials in oncology in the era of big data. Jpn J Clin Oncol 5: 323-327. [Crossref]

26. Murata K, Hinotsu S, Hamada S, Ezoe Y, Muto M, et al. (2015) The changing pattern of dispensing branded and generic drugs for the treatment of gastroesophageal reflux disease between 2006 and 2011 in Japan: a retrospective cohort study. BMC Health Serv Res 15: 76. [Crossref]

27. Katada H, Yukawa N, Urushihara H, Tanaka S, Mimori T, Kawakami K (2015) Prescription patterns and trends in anti-rheumatic drug use based on a large-scale claims database in Japan. Clin Rheumatol 34: 949-956. [Crossref]

28. Derks J, Schaller D, Hakansson J, Wennström JL, Tomasi C, Berglundh T (2016) Effectiveness of implant therapy analzed in a Swedish population: Prevalence of periimplantitis. J Dent Res 95: 43-49. [Crossref]

Copyright: (C2017 Nagahisa K. This is an open-access article distributed under the terms of the Creative Commons Attribution License, which permits unrestricted use, distribution, and reproduction in any medium, provided the original author and source are credited. 